\section{Troubleshooting Forum}

\author{
Molecular Biology Techniques Q\&A
}

\section{Protein Purification: Ion Exchange}

This month's question from the Molecular Biology Forums (online at molecularbiology. forums.biotechniques.com) comes from the "Protein Methods" section. Entries have been edited for concision and clarity. Mentions of specific products and manufacturers have been retained from the original posts, but do not represent endorsements by, or the opinions of, BioTechniques.

My protein gets lost during ion exchange. How can I recover it? (Thread 26631)

Q I am working with granulocyte colony-stimulating factor (G-CSF) protein, which has a pI of 5.6-6.1. To purify it, I solubilize the inclusion bodies in $8 \mathrm{M}$ urea and $0.1 \mathrm{M}$ cysteine and then dilute the solution 1:20 in refolding buffer $(0.1 \%$ Tween $20, \mathrm{pH}$ 8.2). After that, I use the ProFlux M12 to concentrate the protein, skipping the diafiltration step. Finally I adjust the $\mathrm{pH}$ to 4.5 and load it onto source $15 \mathrm{~S}$ resin, which is a strong cation exchanger.

My problem is that I do not observe a peak when performing ion exchange, indicating that I am not recovering the protein. The HPLC and absorbance readings on the concentrate I load into the column show the presence of the protein, so it must be lost during the ion exchange step. I use $25 \mathrm{mM}$ sodium acetate, $\mathrm{pH} 4.5$ for my loading buffer and elute with the same buffer plus $0.5 \mathrm{M} \mathrm{NaCl}$. No protein is lost in the flow-through. Even using 2-M NaCl washes did not release the protein from the column. If I perform a wash with $\mathrm{NaOH}$, I can see a peak, but this is of no value since I cannot analyze it; it is too alkaline and can't be used for SDS-PAGE or HPLC.

What could be causing me to lose my protein? Is it in fact lost during ion exchange, or is some other step contributing to the problem? Can anyone offer advice on how to recover the protein?

A Based on my experience with ion exchange, it sounds like you have aggregates in your sample that are getting trapped inside of the column. You might be able to get them out if you increase the pressure. Try spinning your samples at high speed or perform ultrafiltration on the sample. Following those steps, you should have the protein in the pellet or in the filter, enabling recovery for downstream uses.

The problem may also be solved by changing your method for protein expression. I don't know what expression system you are using, but when I expressed GM-CSF and G-CSF in bacteria in the past I used the pin-OMP vector for secretion to the periplasm from Professor M. Inouye (University of Medicine and Dentistry, New Brunswick, NJ, USA). I induced with low levels of IPTG at $28^{\circ} \mathrm{C}$. Using this system, I obtained a high proportion of soluble protein that eluted at $200 \mathrm{mM} \mathrm{NaCl}$. Aggregates that showed the same patterns in native PAGE, but not under reducing conditions, eluted at $1 \mathrm{M}$, so they are most likely the result of multimerization.

Denaturing and refolding the protein often leads to low output, so it is best to only denature and refold when all other possibilities of expression have failed. Try expressing with lighter metabolic conditions regardless of the expression system; it is better to have low levels of soluble expression than a huge amount of insoluble protein that is hard to work with.

A While I agree that it is best to avoid denaturing and refolding a protein, I presented your difficulties to a colleague who has a lot of experience in purifying G-CSF and he usually denatures with $6 \mathrm{M}$ guanidinium chloride. After several rounds of dialysis with reducing $\mathrm{HCl}$-guanidinium, he charges $\mathrm{Q}$ sepharose at $\mathrm{pH}$. So you should be able to successfully elute your protein even if you have to denature and refold.

\section{biocision the coolprep company}

\section{CryoPrep System}

\section{Ice-Free / Alcohol-Free CryoPreservation}
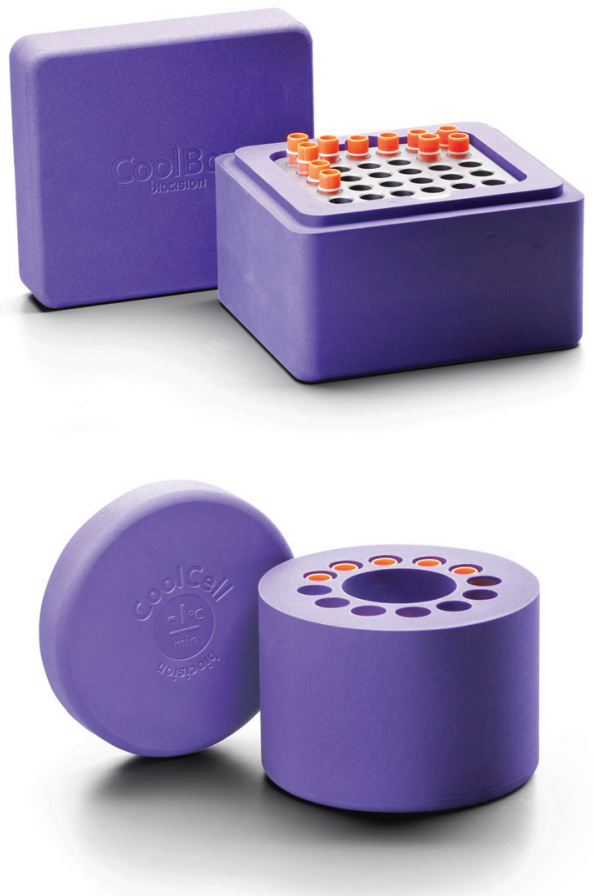

Includes:

\section{CoolBox 30}

Ice-free cooling container for use on benchtop or in the hood

\section{CoolRack CFT}

Thermo-conductive cryo vial module with locking wells that allow one-hand vial opening/closing

\section{CoolCell}

Alcohol-free consistent $-1^{\circ} \mathrm{C} /$ minute cell freezing container 
A You are assuming that your protein is fully refolded and will remain soluble on the ion exchange column, which may not be correct.

My guess is that when the urea moved away from the protein, the protein precipitated and got held up by the grid netting.

I recommend that you try dialysis of the refolded protein against $25 \mathrm{mM}$ sodium acetate, $\mathrm{pH} 4$.5; centrifuge it to remove any precipitate formed, and then load it on the column. I know that you will be dealing with a large volume, but if you use the largest size of dialysis tubing and a 5-gallon bucket, it should work. I have done this successfully in the past.

You probably won't need the concentration step because the ion exchange resin will concentrate the protein for you.

A Have you analyzed every step throughout the experiment to determine exactly where the protein gets lost? You need to check the inclusion bodies, the urea-dissolved inclusion bodies, the refolded protein fraction, the concentrated fraction, the flow through from the ion exchange column, etc. You mentioned using absorbance to check for the presence of your protein, but that is not enough. You should use SDS-PAGE to specifically identify where you are losing the protein. Then you can more effectively focus your troubleshooting efforts to solve the problem.

Q I analyzed each step with SDS-PAGE and HPLC. This showed that I did not lose the protein in the flow-through. HPLC showed a good peak for the protein at about $500-600 \mu \mathrm{g} / \mathrm{mL}$. I loaded $300-400 \mathrm{~mL}$ into the ion exchange column, but did not recover the protein on elution. I only get the protein when washing in the reverse direction with $\mathrm{NaOH}$ where I can see a peak in AKTA, but SDS-PAGE only showed a smeared lane, so I am unable to analyze it.

A Flow reversal helps to remove a protein from the top of the column, so it appears likely that your protein precipitated and stayed at the top of your column. The $\mathrm{NaOH}$ will denature your protein, so the smear on the gel is expected.
You should be able to fix this by keeping urea in your sample and column buffers, which will ensure that your protein remains soluble.

Q Is it possible to do ion exchange with urea? How do I modify my procedures to accommodate that?

A Yes, you can run an ion-exchange column in the presence of urea. When making the loading and elution buffers, you will first need to deionize the urea and then add the buffer salts.

Q I am not familiar with that method, so I would appreciate some guidance. What does it mean to deionize urea? How do I do that? How much urea should I use in my loading and elution buffers?

A While urea has no charge, it decomposes into charged components with time. You just need to deionize the urea with a mixed-bed resin and then use the deionized urea solution (just as you would use deionized water) to make the buffers, adding the required amounts of buffer salts and adjusting the $\mathrm{pH}$. This should allow your protein to move into the column and elute at the end.

A I deionize urea by stirring the urea solution with Rexyn I-300, a mixed-bed ion exchange resin, for $\sim 1 \mathrm{~h}$ at room temperature. I think I usually use $3 \mathrm{~g} / \mathrm{L}$, but it might be $30 \mathrm{~g} / \mathrm{L}$. It should be listed in the product information.

You need to use at least $4 \mathrm{M}$ urea in the buffers. Before running a column, you should check to make sure that your protein remains soluble at that concentration. I usually use $6 \mathrm{M}$ urea in my buffers, but I am working with different proteins from yours.

Selected and edited by Kristie Nybo, Ph.D. 暞

BioTechniques 49:869-871 (December 2010) doi 10.2144/000113565

To purchase reprints of this article, contact: carmelitag@fosterprinting.com

\section{WD WHEATON | CryoELITE ${ }^{\mathrm{TM}}$ Cryogenic Vials}
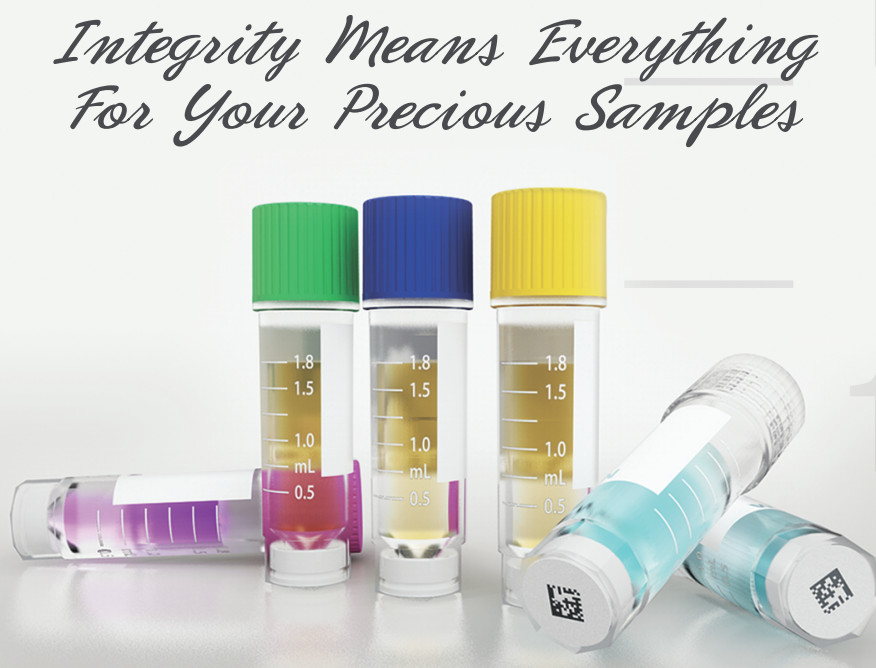

2D Data Matrix Bar Code Bottom Insert for sample traceability and automated systems Unrivaled Cap Seal exceeds DOT and IATA regulations

Loctagon $^{\mathrm{TM}}$ Vial Skirt provides stability in the freestanding position 